This item was submitted to Loughborough's Research Repository by the author.

Items in Figshare are protected by copyright, with all rights reserved, unless otherwise indicated.

\title{
Molecular dynamics modelling of radiation damage in normal, partly inverse and inverse spinels
}

PLEASE CITE THE PUBLISHED VERSION

PUBLISHER

(C) Elsevier

LICENCE

CC BY-NC-ND 4.0

\section{REPOSITORY RECORD}

Bacorisen, Dnyansingh, Roger Smith, J.A. Ball, R.W. Grimes, B.P. Uberuaga, K.E. Sickafus, and W.T. Rankin. 2019. "Molecular Dynamics Modelling of Radiation Damage in Normal, Partly Inverse and Inverse Spinels". figshare. https://hdl.handle.net/2134/2435. 


\title{
Molecular Dynamics Modelling of Radiation Damage in Normal, Partly Inverse and Inverse Spinels
}

\author{
D. Bacorisen and Roger Smith \\ Department of Mathematical Sciences, Loughborough University, Loughborough, \\ Leicestershire LE11 3TU, UK
}

J. A. Ball and R.W. Grimes

Department of Materials, Imperial College, Prince Consort Road, London SW7 2BP

B.P. Uberuaga and K. E. Sickafus

Los Alamos National Laboroatory, Los Alamos, New Mexico 87545 USA

W. T. Rankin

Department of Electrical and Computer Engineering, Duke University, Box 90291, Durham, NC 27708, USA

\begin{abstract}
The radiation response of perfect crystals of $\mathrm{MgAl}_{2} \mathrm{O}_{4}$, partially inverted $\mathrm{MgGa}_{2} \mathrm{O}_{4}$ and fully inverse $\mathrm{MgIn}_{2} \mathrm{O}_{4}$ were investigated using molecular dynamics. Dynamical cascades were initiated in these spinels over a range of trajectories with energies of $400 \mathrm{eV}$ and $2 \mathrm{keV}$ for the primary knock-on event. Collision cascades were set up on each of the cation and anion sublattices and were monitored up to $10 \mathrm{ps}$. Simulations in the normal $\mathrm{MgAl}_{2} \mathrm{O}_{4}$ spinel for the $2 \mathrm{keV}$ energy regime resulted in similar defect structures as obtained at the post-threshold $400 \mathrm{eV}$ energies, with little clustering occurring. The predominant defect configurations were split interstitials and cation antisites. For the inverse spinels, a much wider variety of lattice imperfections was observed. More defects were also produced due to the formation of interstitialvacancy cation chains and oxygen crowdions.
\end{abstract}

Key words: collisions cascades, spinel, defect formation PACS: 61.72.Ji, 61.80.-x, 61.82.Ms 


\section{Introduction}

Magnesium aluminate $\mathrm{MgAl}_{2} \mathrm{O}_{4}$ spinel is a ceramic oxide that has demonstrated strong radiation resistance to amorphisation and to the formation of defect clusters and dislocation loops [1] [2]. Recent irradiation experiments conducted by Matsumura et al. revealed disorder occurring over the cation sublattices, but the crystal structure remained stable in the damaged area [3] after $1 \mathrm{MeV} \mathrm{Ne}{ }^{+}$irradiation to a dose of $4.5 \times 10^{20}$ ions $/ \mathrm{m}^{2}$.

The term spinel generally refers to the class of compounds with the molecular formula $\mathrm{AB}_{2} \mathrm{O}_{4}$, where $\mathrm{A}$ and $\mathrm{B}$ are generally either divalent and trivalent respectively or tetravalent and divalent [4]. Within the cubic closed-packed array of anions, the structure holds two types of interstices: octahedral and tetrahedral. Eight formula units make up a unit cell of spinel, containing a total of 64 tetrahedral interstices and 32 octahedral interstices between the anions [5]. In the perfect normal spinel, $\mathrm{MgAl}_{2} \mathrm{O}_{4}$, all $\mathrm{Mg}^{2+}$ ions occupy one eighth of the tetrahedral positions, and the $\mathrm{Al}^{3+}$ ions occupy half of octahedral interstices with six oxygen nearest neighbours, as shown in Fig.1. The remaining interstices are able to accommodate defect species.
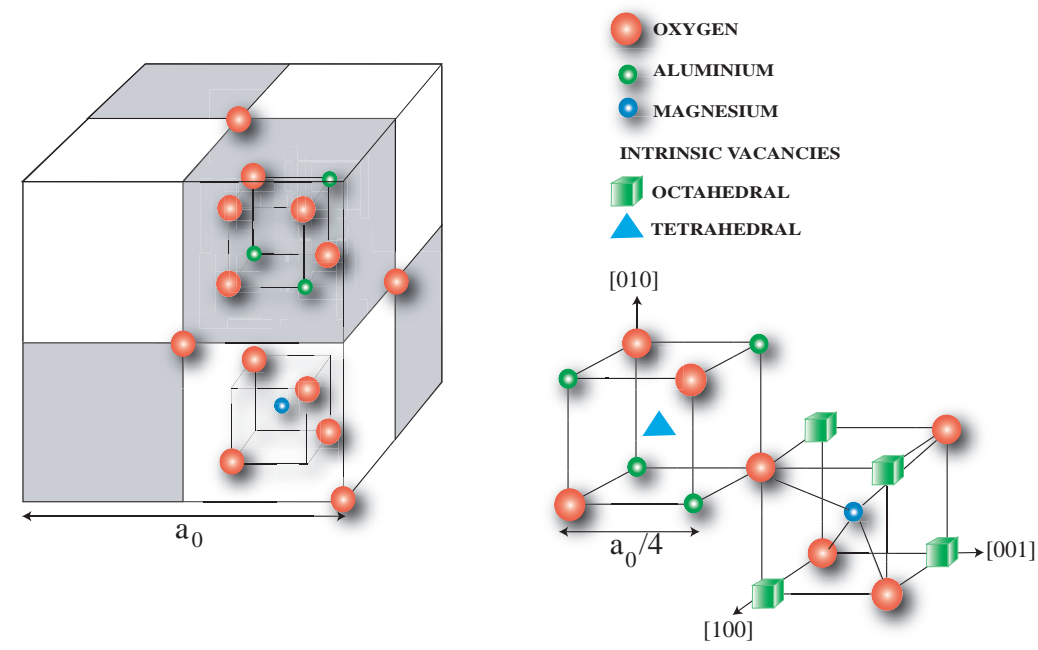

Fig. 1. The structure of spinel (adapted from Sickafus et al. [5]). The unit cell consists of alternate octahedral and tetrahedral structures as shown on the left diagram.

Cationic interchange is one of the factors that explains the radiation tolerance of spinels. This occurs when one divalent cation $\left(\mathrm{Mg}^{2+}\right)$ initially at a tetrahedral site replaces a trivalent cation $\left(\mathrm{Al}^{3+}\right)$ at an octahedral site and vice-versa, resulting in the formation of a pair of antisite defects. Cation antisites are known to have the lowest formation energy as compared to other types of defects in spinels because the degree of local distortion of the crystalline structure resulting from their formation is minimal [6] [7]. The extent of cation disordering is quantified by the inversion parameter $i$, which is the 
fraction of tetrahedral sites occupied by trivalent cations; $i$ ranges from 0 for the normal spinel to 1 for a fully inverse spinel, and relates to the formula $\left[\mathrm{Mg}_{1-i} \mathrm{Al}_{i}\right]\left(\mathrm{Mg}_{i} \mathrm{Al}_{2-i} \mathrm{O}_{4}\right)$, where square brackets indicate the tetrahedral cation sites and curved brackets the octahedral sites.

In this work, we use molecular dynamics (MD) to simulate the damage response of three spinel compounds, namely normal magnesium aluminate, $\mathrm{MgAl}_{2} \mathrm{O}_{4}$, half inverse magnesium gallate $\mathrm{MgGa}_{2} \mathrm{O}_{4}(i=0.5)$ and the fully inverse magnesium indate $\mathrm{MgIn}_{2} \mathrm{O}_{4}(i=1)$. In reality the inversion parameter of $\mathrm{MgAl}_{2} \mathrm{O}_{4}$ is only close to zero at low temperatures and for natural spinel samples that have been able to equilibrate over geological time scales [8] [9]. Synthetic materials exhibit a broad range of inversion parameters from $\approx 0.2-0.4$ [10].

We compare the structural changes in these three compounds and investigate the most common types of defects for energies of $400 \mathrm{eV}$ and $2 \mathrm{keV}$. The simulation is set up by imparting a certain amount of kinetic energy to an atom or ion at the centre of the simulation cell. This atom, known as the primary knock-on atom (PKA), displaces other target atoms along its trajectory and creates a disturbed region consisting of point defects. Details such as the number and distribution of the residual defects together with the mechanisms for defect recombination or aggregation can be extracted from the simulations.

\section{Methodology}

\subsection{Potential}

The ionic spinel crystal was modelled as an ordered array of point masses with formal charges. Electronic contributions were not considered explicitly. The interactions were calculated by a pairwise additive potential energy function comprising of the standard Buckingham potential [11] for short range interactions and the usual Coulomb potential for the long range electrostatic field. In these dynamical cascades, especially in the high energy regimes, the repulsive behaviour of colliding ionic cores at very small separation is taken into account by joining the potential profile to the Ziegler-Biersack-Littmark (ZBL) potential [12]. This is achieved by using a splining function $g\left(r_{i j}\right)$, where $r_{i j}$ denotes the pair separation between ions $i$ and $j$, to ensure continuity of the first and second derivatives for these functions. We have also implemented a smooth cutoff of the Buckingham potential at an interatomic distance greater than $r_{2}$. The potential energy function, $\phi\left(r_{i j}\right)$ and the splining function are given by Eq. (1) and Eq. (2) respectively, where $f_{i}$ are fitted constants. 


\begin{tabular}{c|ccccc}
\hline Pair interactions $(i$ and $j)$ & $A_{i j}(\mathrm{eV})$ & $\rho_{i j}(\AA)$ & $C_{i j}\left(\AA^{6} \mathrm{eV}\right)$ & $r_{0}(\AA)$ & $r_{1}(\AA)$ \\
\hline \hline Mg-O & 1279.69 & 0.29969 & - & 0.15 & 0.8 \\
O-O & 9547.96 & 0.21916 & 32.0 & 0.2 & 1.05 \\
O-Al & 1374.79 & 0.3013 & - & 0.15 & 0.65 \\
O-Ga & 1625.72 & 0.3019 & - & 0.15 & 0.65 \\
O-In & 1595.65 & 0.3296 & 7.402 & 0.45 & 1.10 \\
\hline
\end{tabular}

Table 1

Potential parameters for magnesium aluminate, semi inverse magnesium gallate, and inverse magnesium indate spinels.

$$
\begin{gathered}
\phi\left(r_{i j}\right)= \begin{cases}Z B L & r_{i j}<r_{0} ; \\
g\left(r_{i j}\right) & r_{0} \leq r_{i j}<r_{1} ; \\
A_{i j} \exp \left(-\frac{r_{i j}}{\rho_{i j}}\right)-\frac{C_{i j}}{r_{i j}^{6}}+V\left(r_{i j}\right) & r_{1} \leq r_{i j}<r_{2} ; \\
V\left(r_{i j}\right) & r_{i j} \geq r_{2},\end{cases} \\
g\left(r_{i j}\right)=e^{\left(f_{1}+f_{2} r_{i j}+f_{3} r_{i j}^{2}+f_{4} r_{i j}^{3}+f_{5} r_{i j}^{4}+f_{6} r_{i j}^{5}\right)}
\end{gathered}
$$

In Eq. (1), $V\left(r_{i j}\right)$ denotes the Coulomb potential, and potential parameters $A_{i j}, \rho_{i j}$ and $C_{i j}$ reported in Table 1 , were determined by a multistructurefitting scheme to describe correctly the inversion in these spinels [13] [14]. The cation-cation interactions are purely Coulombic, such that the $A_{i j}$ and $\rho_{i j}$ parameters are zero. The potential gives a lattice parameter of $8.12 \AA$ for $\mathrm{MgAl}_{2} \mathrm{O}_{4}, 8.31 \AA$ for the half-inverse $\mathrm{MgGa}_{2} \mathrm{O}_{4}$ and $8.85 \AA$ for the inverse $\mathrm{MgIn}_{2} \mathrm{O}_{4}$. These values are slightly higher than those reported experimentally in $[15]$.

\subsection{Simulation setup}

The simulations were performed in crystalline structures that reflect the degree of disorder that can be observed experimentally for each material: $i=0$ for $\mathrm{MgAl}_{2} \mathrm{O}_{4}, i=0.5$ for $\mathrm{MgGa}_{2} \mathrm{O}_{4}$ and $i=1$ for $\mathrm{MgIn}_{2} \mathrm{O}_{4}$. For $\mathrm{MgGa}_{2} \mathrm{O}_{4}$ and $\mathrm{MgIn}_{2} \mathrm{O}_{4}$, this was achieved by using a Monte-Carlo energy minimisation technique [16] to generate a $2 \times 1 \times 1$ supercell from which the whole lattice was generated.

The Coulomb sums were calculated using the Distributed Parallel Multipole Tree Algorithm (DPMTA) which is a fast multipole method developed by 
Rankin [17]. In the implementation of the algorithm, we choose not to impose periodic boundary conditions but instead to use a charge-neutral cube and fix the three outer atomic layers. We ensured that the cascades did not interact significantly with the cell boundaries by using sufficiently large cells. Consequently, the $400 \mathrm{eV}$ simulations were carried out using a cubic cell of size $\sim 50$ $\AA$ containing 12331 ions, whereas the $2 \mathrm{keV}$ simulations were performed in a system of size $\sim 100 \AA$ containing 97,669 ions. Before the dynamical cascades were initiated, the system was relaxed for up to $10 \mathrm{ps}$. The cascades were carried out at an initial temperature of $0 \mathrm{~K}$. The knock on event was set up by giving extra kinetic energy to the PKA along a specific crystallographic direction and the simulation was monitored up to $10 \mathrm{ps}$, the time by which most defects had relaxed.

\section{$3 \quad 400 \mathrm{eV}$ cascades}

We simulated $400 \mathrm{eV}$ irradiation events since simulations showed that the higher energy cascades produce sub-cascades with similar defect structures. Because of differences in the atomic masses and displacement energies of the separate sublattices, 9 simulations were performed for each of the $\mathrm{O}^{2-}, \mathrm{Mg}^{2+}$ and $\mathrm{B}^{3+}$ PKAs where $\mathrm{B}=\mathrm{Al}$, Ga or In. The residual defects for each PKA reported in Table 2 are averaged and are representative of the damage per simulation. Interstitials, vacancies and antisite defects are denoted using the simplified Kröger-Vink notation [18]. In the table a split interstitial is counted as two interstitials and a vacancy, not a single defect.

\section{$3.1 \mathrm{MgAl}_{2} \mathrm{O}_{4}$}

Some results concerning cascades in normal spinel have been previously reported in [7]. The maximum number of displaced ions typically occurred around 100-150 fs after the PKA was set in motion. Most displaced ions recombined to lattice sites within the first picosecond leaving only a few surviving defects. For the $\mathrm{Mg}$ PKA, the predominant defects occurring were the $\mathrm{Mg}$ split interstitial $\mathrm{Mg}_{\mathrm{i}}-\mathrm{V}_{\mathrm{Mg}}^{\prime \prime}-\mathrm{Mg}_{\mathrm{i}}$, and the isolated $\mathrm{Mg}$ vacancy $\mathrm{V}_{\mathrm{Mg}}^{\prime \prime}$. In normal spinel, cation split interstitials centred about a tetrahedral $\mathrm{Mg}$ vacancy were common. This configuration is usually aligned along $<110>$ so that the two interstitials could fill the space of the neighbouring unoccupied octahedral interstices. Such a situation is illustrated in Fig 2(a) with a split Mg interstitial separated from an isolated vacancy with one $\mathrm{Al}$ and one $\mathrm{Mg}$ antisites. Table 2 shows that the Mg PKA created a total of 1 cation antisite per simulation for this energy. Out of the 9 trajectories, 3 ended up without any damage to the crystal when $\mathrm{O}$ was the primary knock-on atom. The remaining cascades 


\begin{tabular}{c|c|cc|ccc|ccc}
\hline Compound & $\mathrm{PKA}$ & $\mathrm{Mg}_{\mathrm{B}}$ & $\mathrm{B}_{\mathrm{Mg}}$ & $\mathrm{Mg}_{\mathrm{i}}$ & $\mathrm{O}_{\mathrm{i}}^{\prime \prime}$ & $\mathrm{B}_{\mathrm{i}}^{\cdots}$ & $\mathrm{V}_{\mathrm{Mg}}^{\prime \prime}$ & $\mathrm{V}_{\mathrm{O}}$ & $\mathrm{V}_{\mathrm{B}}^{\prime \prime \prime}$ \\
\hline \hline $\mathrm{MgAl}_{2} \mathrm{O}_{4}$ & $\mathrm{Mg}^{2+}$ & $\mathbf{0 . 6 7}$ & 0.44 & $\mathbf{2 . 0}$ & 0.22 & 0.22 & $\mathbf{2 . 2 2}$ & 0.22 & 0.00 \\
& $\mathrm{O}^{2-}$ & 0.11 & 0.11 & 0.00 & $\mathbf{1 . 1 1}$ & 0.00 & 0.00 & $\mathbf{1 . 1 1}$ & 0.00 \\
& $\mathrm{Al}^{3+}$ & 0.56 & $\mathbf{1 . 1 1}$ & $\mathbf{1 . 2 2}$ & 0.89 & 0.33 & 0.67 & 0.89 & 0.89 \\
\hline \hline $\mathrm{MgGa}_{2} \mathrm{O}_{4}$ & $\mathrm{Mg}^{2+}$ & $\mathbf{1 . 3 3}$ & 0.67 & 1.56 & 1.44 & $\mathbf{2 . 0 0}$ & $\mathbf{2 . 2 2}$ & 1.44 & 1.33 \\
& $\mathrm{O}^{2-}$ & 0.22 & $\mathbf{0 . 3 3}$ & 1.00 & $\mathbf{3 . 1 1}$ & 0.78 & 1.11 & $\mathbf{3 . 1 1}$ & 0.89 \\
& $\mathrm{Ga}^{3+}$ & 0.44 & $\mathbf{1 . 0 0}$ & $\mathbf{3 . 3 3}$ & 1.89 & 2.56 & 2.78 & 1.89 & $\mathbf{3 . 1 1}$ \\
\hline \hline \multirow{2}{*}{$\mathrm{MgIn}_{2} \mathrm{O}_{4}$} & $\mathrm{Mg}^{2+}$ & $\mathbf{0 . 3 3}$ & 0.22 & 1.33 & $\mathbf{1 . 7 8}$ & 1.56 & 1.11 & 1.78 & 1.78 \\
& $\mathrm{O}^{2-}$ & 0.00 & $\mathbf{0 . 1 1}$ & 0.33 & $\mathbf{3 . 2 2}$ & 1.11 & 0.33 & $\mathbf{3 . 2 2}$ & 1.22 \\
& $\mathrm{In}^{3+}$ & 0.33 & $\mathbf{0 . 8 9}$ & 0.89 & $\mathbf{3 . 1 1}$ & 2.11 & 0.33 & $\mathbf{3 . 1 1}$ & 2.67 \\
\hline
\end{tabular}

Table 2

The residual defects obtained at $400 \mathrm{eV}$ for the three spinels. The defects tabulated are antisites, interstitials and vacancies respectively, and the bold characters refer to the predominant defect species of each type.

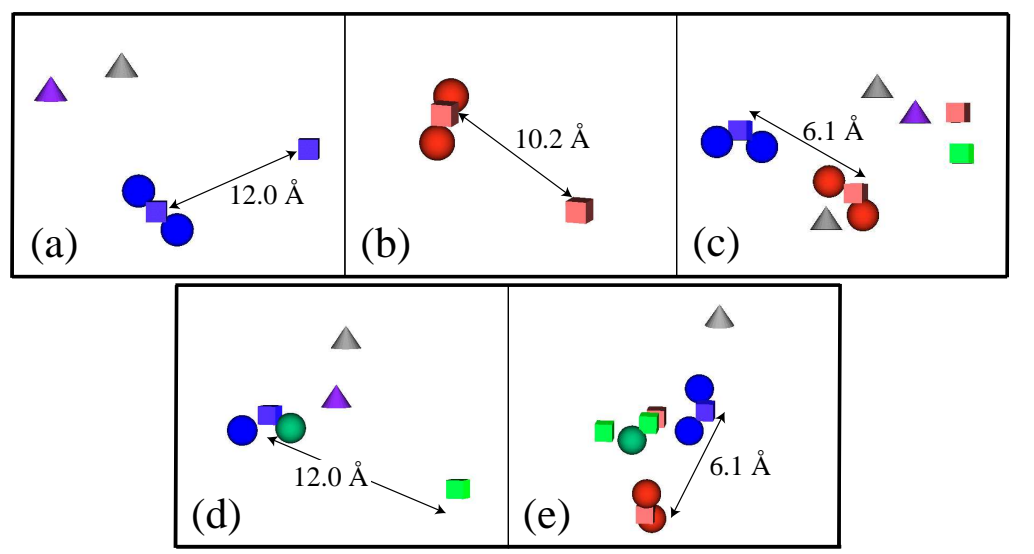

Fig. 2. Typical defects observed at $400 \mathrm{eV}$ in $\mathrm{MgAl}_{2} \mathrm{O}_{4}$ for a $\mathrm{Mg}^{2+} \mathrm{PKA}$ initiated along $\langle 135\rangle$ (a), an $\mathrm{O}^{2-}$ PKA along $\langle 173\rangle$ (b), an $\mathrm{Al}^{3+}$ PKA along $\langle 175\rangle$ (c), an $\mathrm{Al}^{3+}$ PKA directed along $\langle 123\rangle$ (d) an $\mathrm{Al}^{3+}$ PKA along $\langle 173\rangle$ (e). Interstitials are denoted by spheres and vacancies are shown as cubes. The green colour refers to the ternary cation $\mathrm{B}$ (here $\mathrm{B}=\mathrm{Al}$ ); $\mathrm{Mg}$ defects are coloured blue and $\mathrm{O}$ defects red. Cones represent antisites (purple - $\mathrm{Mg}_{\mathrm{B}}$; grey - $\mathrm{B}_{\mathrm{Mg}}$ ). The same colour scheme applies for all the three spinels.

typically resulted in 1 anion split interstitial $\mathrm{O}_{\mathrm{i}}^{\prime \prime}-\mathrm{V}_{\mathrm{O}}-\mathrm{O}_{\mathrm{i}}^{\prime \prime}$ with an isolated $\mathrm{V}_{\mathrm{O}}$ ” (see Fig. 2(b)). The Al PKA produced more $\mathrm{Al}$ antisites as compared to $\mathrm{Mg}$ antisites. The other defect structures obtained were cation antisites, $\mathrm{Mg}$ and $\mathrm{O}$ split interstitials as shown in Fig. 2(c), and a mixed $\mathrm{Mg}-\mathrm{Al}$ split interstitial centred about a $\mathrm{Mg}$ vacancy (Fig. 2(d)). Two simulations resulted in a defect configuration including an $\mathrm{Al}$ interstitial trapped between 2 adjacent $\mathrm{Al}$ vacancies. Such a situation is illustrated in Fig. 2(e). Cation split inter- 
stitials centred about an Al vacancy did not occur. Oxygen split interstitials could reform with neighbouring vacancies if the axis of the split interstitial was in the direction of the $\mathrm{O}$ vacancies, leading to a one-dimensional diffusion mechanism. The migration energy for this transition to occur was found to be $0.29 \mathrm{eV}$. Conversely if the $\mathrm{O}$ split interstitial had its axis perpendicular to that joining its central vacancy to the neighbouring $\mathrm{O}$ vacancy as shown in Fig. 2(b), then an extra $0.63 / 0.67 \mathrm{eV}$ was required for the configuration to align along the favourable direction before migrating (these energies refer to at least two mechanisms for the split interstitial to rotate). Al antisites could easily pin the $\mathrm{O}$ split interstitial to prevent the latter from migrating (see Fig. $2(\mathrm{c}))$. The two defects have a positive binding energy of $1.65 \mathrm{eV}$.

\subsection{Half inverse $\mathrm{MgGa}_{2} \mathrm{O}_{4}$}

Figure 3 shows the damage in the half inverse $(i=0.5)$ magnesium gallate when choosing a $\mathrm{Mg}^{2+}, \mathrm{O}^{2-}$ and $\mathrm{Ga}^{3+} \mathrm{PKA}$. In this crystal, half of the occupied tetrahedral interstices were taken up by the $\mathrm{Ga}^{3+}$ ions. In the normal spinel, this site was occupied solely by the $\mathrm{Mg}$ ion and was the only favourable site where cation split interstitials could form. Cation split interstitials centred about a tetrahedral Ga vacancy were observed in the magnesium gallate spinel (see pure Ga split interstitial in Fig. 3(a)).

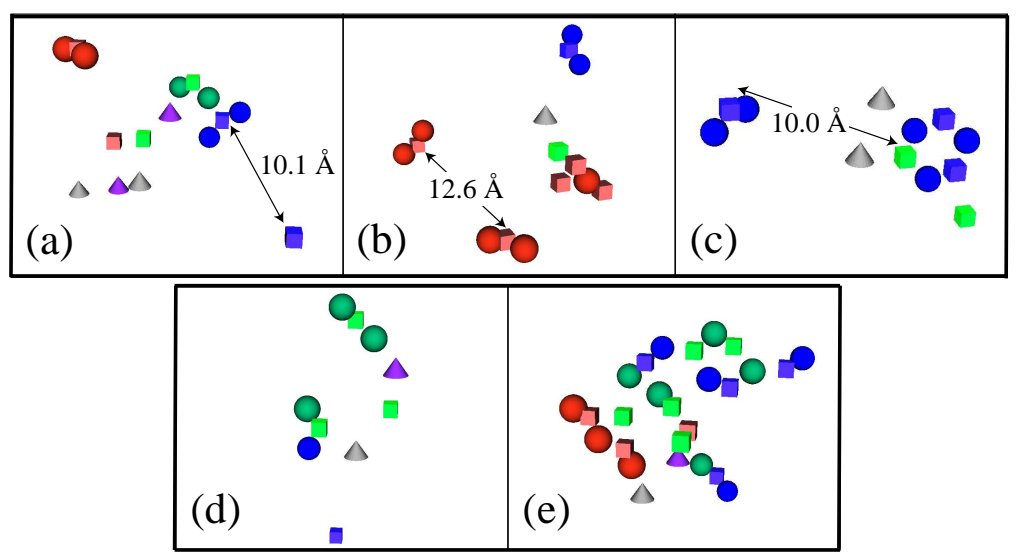

Fig. 3. The pictures show the damage after 5 ps for a PKA energy of $400 \mathrm{eV}$ in the gallate spinel. (a) $\mathrm{Mg}^{2+}$ PKA along $\langle 123\rangle$ resulting in the formation of pure $\mathrm{O}$, $\mathrm{Ga}$, and $\mathrm{Mg}$ split interstitials, one $\mathrm{Ga}-\mathrm{O}$ vacancy pair and cation antisites; (b) $\mathrm{O}^{2-}$ PKA along $\langle 175\rangle$; (c) $\mathrm{Ga}^{3+}$ PKA along $\langle 210\rangle$ forming a distinct 'ring' structure; (d) $\mathrm{Mg}^{2+}$ PKA along $\langle 751\rangle$; (e) $\mathrm{Ga}^{3+}$ PKA along $\langle 173\rangle$ creating disorder on the cation sublattice.

For the $\mathrm{Mg}^{2+} \mathrm{PKA}$, the common defects consisted of $\mathrm{O}, \mathrm{Mg}, \mathrm{Ga}$ and mixed $\mathrm{Mg}-\mathrm{Ga}$ split interstitials centred about either a $\mathrm{Mg}$ vacancy or a Ga vacancy. Fig. 3(a) exemplifies the final damage obtained with a Mg PKA. The simu- 
lations initiated by $\mathrm{O}^{2-}$ PKAs produced more damage on the $\mathrm{O}$ sublattice, the defects being mainly $\mathrm{O}$ split interstitials or $\mathrm{O}$ crowdions oscillating onedimensionally in the $\langle 110>$ directions. Fig. $3(\mathrm{~b})$, gives an example where the $\mathrm{O}$ interstitial settled at a tetrahedral interstice between $3 \mathrm{O}$ vacancies and 1 Ga vacancy. For the $\mathrm{Ga}^{3+}$ PKA more cation defects were obtained. Typical defects were interstitial-vacancy 'crowdion' chains, with the interstitials trapped at unoccupied interstices between the vacancies. Fig. 3(c) illustrates a 'ring' structure made up of $3 \mathrm{Mg}_{\mathrm{i}}, 2 \mathrm{~V}_{\mathrm{Mg}}^{\prime \prime}$ and $1 \mathrm{~V}_{\mathrm{Ga}}^{\prime \prime \prime}$. Closer inspection revealed that the $3 \mathrm{Mg}$ interstitials settled at tetrahedral interstices between the octahedral vacancies. This defect formed around the 1 ps time mark following the cascade initiation. Over the whole set, more defects were seen in this compound as compared to the normal spinel. This difference occurs because of extended split interstitials on the cation sublattice, anion crowdions, and also the tendency of an isolated $\mathrm{O}$ vacancy to push the nearest neighbour tetrahedral cation slightly off its site resulting in an extra vacancy and interstitial.

\subsection{Inverse $\mathrm{MgIn}_{2} \mathrm{O}_{4}$}

Table 2 shows a smaller number of antisite defects produced in the inverse indate spinel as compared to the normal and half-inverse spinel. In this case, the irradiated crystals contained mainly anion and cation split interstitials and crowdions as in the half inverse spinel. The cation split interstitials were centred about an In vacancy, the latter being an initially occupied tetrahedral site. Figure 4 illustrates some of the final structures for 3 simulations.

The average number of interstitials created by a $\mathrm{Mg}^{2+}$ PKA for a $400 \mathrm{eV}$ cascade in magnesium indate is 1.33 for $\mathrm{Mg}, 1.78$ for $\mathrm{O}$ and 1.56 for In. The interstitials formed $\mathrm{Mg}_{\mathrm{i}}^{\ddot{-}}-\mathrm{V}_{\mathrm{In}}^{\prime \prime \prime}-\mathrm{In}_{\mathrm{i}} \cdots, \mathrm{O}_{\mathrm{i}}^{\prime \prime}-\mathrm{V}_{\mathrm{O}}{ }^{-}-\mathrm{O}_{\mathrm{i}}^{\prime \prime}$ and $\mathrm{In}_{\mathrm{i}}^{\cdots}-\mathrm{V}_{\mathrm{In}}^{\prime \prime \prime}-\mathrm{In}_{\mathrm{i}}{ }^{\cdots}$ structures and $\mathrm{O}$ crowdions. No split interstitials around an $\mathrm{Mg}$ octahedral vacancy were found just as no split interstitials were observed around an octahedral Al site in normal $\mathrm{MgAl}_{2} \mathrm{O}_{4}$. The $\mathrm{O}^{2-}$ PKAs produced damage mainly on the oxygen sublattice. An average of $3.2 \mathrm{O}$ interstitials were created per trajectory as compared to 0.3 and 1.1 for $\mathrm{Mg}$ and In interstitials respectively. For the 9 trajectories considered only 1 In antisite was observed. For an O PKA initiated along $\langle 123\rangle$ the irradiated lattice ended as shown in Fig. 4(b), with the formation of $1 \mathrm{O}$ divacancy defect, a cation chain, an isolated $\mathrm{Mg}$ vacancy and an $\mathrm{O}$ split interstitial. The cation chain was created around $1.3 \mathrm{ps}$ with the interstitials occupying octahedral interstices. Near the chain an O interstitial is trapped at a tetrahedral interstice between two $\mathrm{O}$ vacancies. Similar defects were obtained when the PKA was $\mathrm{In}^{3+}$. In this case, the ballistic phase involved more displaced ions. For a PKA orientation of $\langle 731\rangle$, the final damage is presented in Fig 4(c). In this case the O crowdion structure hops around during the period of the simulation and does not settle to a stable configu- 
ration. Over the whole set, $\mathrm{O}$ defects were predominant as reported in Table 2 .

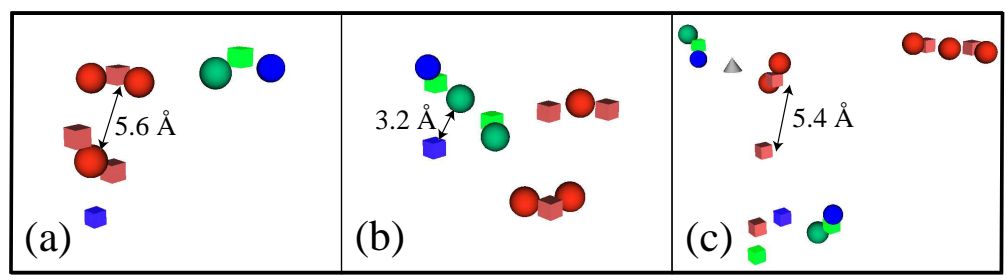

Fig. 4. Some defect structures in magnesium indate for $400 \mathrm{eV}$ using (a) $\mathrm{Mg}^{2+} \mathrm{PKA}$ along $\langle 210\rangle$, (b) $\mathrm{O}^{2-}$ directed along $\langle 123\rangle$ and (c) $\mathrm{In}^{3+}$ PKA along $\langle 731\rangle$.

\section{$4 \quad 2 \mathrm{keV}$ cascades}

A total of 12 trajectories per compound was run for PKA energies of $2 \mathrm{keV}$. The simulations were equally divided among the PKA species resulting in 4 simulations for each sublattice. The average number of defects per simulation is reported in Table 3 and Fig. 5 shows the residual damage for the three spinels. Complex defect structures and clusters occurred in the inverse spinels for certain PKA trajectories, especially when the PKA was the ternary cation.

\begin{tabular}{c|c|cc|ccc|ccc}
\hline Compound & $\mathrm{PKA}$ & $\mathrm{Mg}_{\mathrm{B}}$ & $\mathrm{B}_{\mathrm{Mg}}$ & $\mathrm{Mg}_{\mathrm{i}}$ & $\mathrm{O}_{\mathrm{i}}^{\prime \prime}$ & $\mathrm{B}_{\mathrm{i}}^{* *}$ & $\mathrm{~V}_{\mathrm{Mg}}^{\prime \prime}$ & $\mathrm{V}_{\mathrm{O}}^{\prime \prime}$ & $\mathrm{V}_{\mathrm{B}}^{\prime \prime \prime}$ \\
\hline \hline $\mathrm{MgAl}_{2} \mathrm{O}_{4}$ & $\mathrm{Mg}^{2+}$ & $\mathbf{2 . 2 5}$ & 1.75 & $\mathbf{7 . 7 5}$ & 6.75 & 2.00 & $\mathbf{8 . 2 5}$ & 6.75 & 1.50 \\
& $\mathrm{O}^{2-}$ & 0.75 & 0.75 & 2.00 & $\mathbf{8 . 0 0}$ & 3.25 & 2.00 & $\mathbf{8 . 0 0}$ & 3.25 \\
& $\mathrm{Al}^{3+}$ & 2.25 & $\mathbf{2 . 7 5}$ & 4.50 & 5.25 & $\mathbf{6 . 0 0}$ & 4.00 & 5.25 & $\mathbf{6 . 5 0}$ \\
\hline \hline $\mathrm{MgGa}_{2} \mathrm{O}_{4}$ & $\mathrm{Mg}^{2+}$ & 5.75 & $\mathbf{6 . 0 0}$ & $\mathbf{1 2 . 0 0}$ & 8.25 & 7.50 & $\mathbf{1 1 . 7 5}$ & 8.25 & 7.75 \\
& $\mathrm{O}^{2-}$ & 3.75 & $\mathbf{4 . 2 5}$ & 7.75 & $\mathbf{1 2 . 2 5}$ & 8.25 & 7.25 & $\mathbf{1 2 . 2 5}$ & 8.75 \\
& $\mathrm{Ga}^{3+}$ & $\mathbf{6 . 2 5}$ & 6.00 & $\mathbf{1 7 . 5}$ & 10.25 & 14.25 & $\mathbf{1 7 . 7 5}$ & 10.50 & 13.75 \\
\hline \hline \multirow{2}{*}{$\mathrm{MgIn}_{2} \mathrm{O}_{4}$} & $\mathrm{Mg}^{2+}$ & 2.75 & $\mathbf{3 . 5 0}$ & 4.50 & $\mathbf{1 8 . 0 0}$ & 8.50 & 3.75 & $\mathbf{1 8 . 0 0}$ & 9.25 \\
& $\mathrm{O}^{2-}$ & 3.25 & 3.25 & 2.75 & $\mathbf{1 5 . 7 5}$ & 9.00 & 2.75 & $\mathbf{1 5 . 7 5}$ & 9.00 \\
& $\mathrm{In}^{3+}$ & 4.75 & $\mathbf{6 . 0 0}$ & 5.25 & 15.75 & 15.75 & 4.00 & 15.75 & $\mathbf{1 7 . 7 5}$ \\
\hline
\end{tabular}

Table 3

The table shows the average number of surviving defects for a $2 \mathrm{keV}$ PKA. The numbers in each row are averages of 4 simulations for each PKA. 


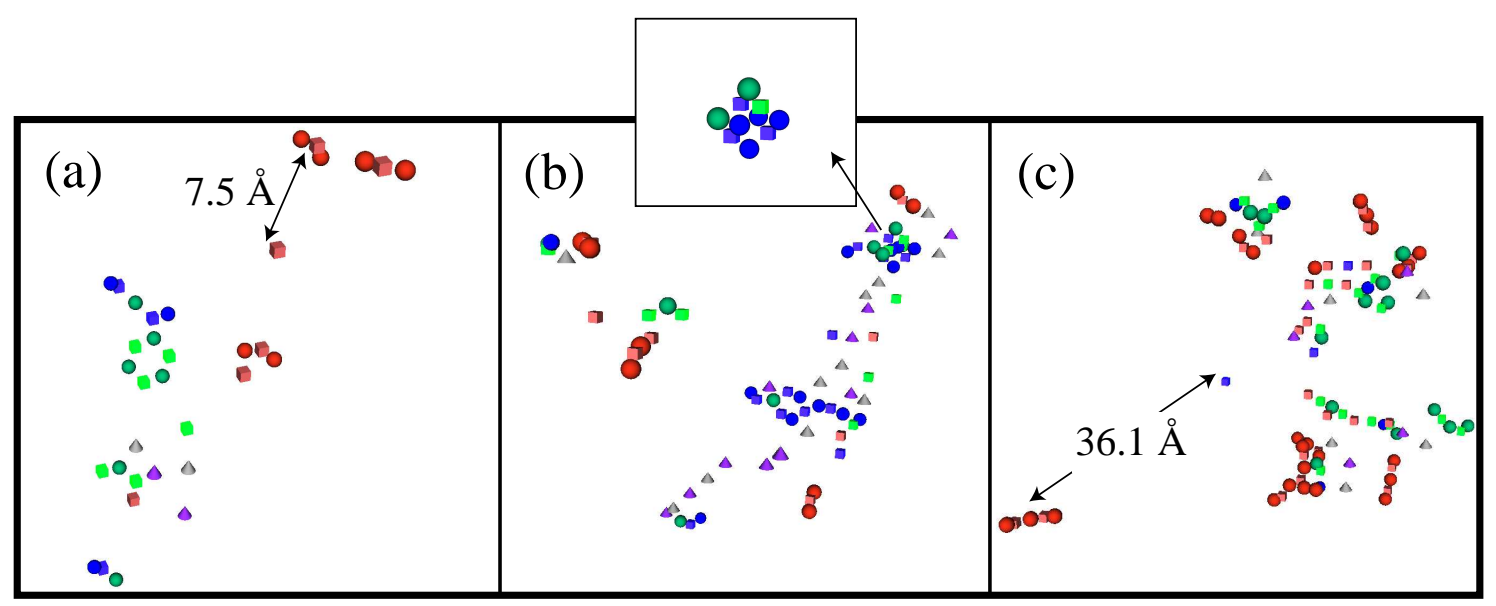

Fig. 5. Residual defects from a $2 \mathrm{keV}$ event in the (a) normal spinel - cascade initiated by an Al PKA along $\langle 210\rangle$, (b) gallate spinel resulting from a Mg PKA set up in the $\langle 751\rangle$ direction, (c) inverse $\mathrm{MgIn}_{2} \mathrm{O}_{4}$ for a $\mathrm{Mg} \mathrm{PKA}$ along $\langle 435\rangle$. In general, the normal spinel ended with the least damage, while complex defect clusters were formed in the inverse spinels.

$4.1 \mathrm{MgAl}_{2} \mathrm{O}_{4}$

Damage resulting from $2 \mathrm{keV}$ cascades in $\mathrm{MgAl}_{2} \mathrm{O}_{4}$ was characterised by an increased number, but similar defect structures, as the $400 \mathrm{eV}$ cascades. For example, the $\mathrm{O}^{2-}$ PKAs produced little damage on the cation sublattice with a small fraction of antisites defects as shown in Table 3. The cation PKAs created more disorder over their respective sublattices and also a considerable amount of anion defects. All the anion defects were of split interstitial form, while the cation defects could be observed to form split interstitials centred about an $\mathrm{Mg}$ vacancy and defect structures over the $\mathrm{Al}$ sublattice. In the latter case, defects with an $\mathrm{Al}$ ion trapped between two vacancies were observed, and a few ring structures were obtained consisting of $3 \mathrm{Al}_{\mathrm{i}}^{\cdots}$ and $3 \mathrm{~V}_{\mathrm{Al}}^{\prime \prime \prime}$ (see Fig. 5a). Detailed analysis of these ring defects using temperature accelerated dynamics [19] showed a formation energy of $10.24 \mathrm{eV}$ and a barrier of $1.23 \mathrm{eV}$ for the structure to annihilate. The ring defects alter only slightly the perfect lattice but absorb a considerable amount of energy in their creation. The existence of such defect clusters could contribute significantly to the radiation tolerance of spinel.

\section{2 $\mathrm{MgGa}_{2} \mathrm{O}_{4}$}

More antisites were generated in this compound as compared to the normal and fully inverse spinels. Substantial disorder on the cation sublattice formed, with interstitial-vacancy chains, where the interstitials were trapped at intrin- 
sic vacancy interstices. Ring structures involving both cations were observed with many defect clusters. Fig. 5(b) results from a Mg PKA directed along $\langle 751\rangle$. This cascade instantaneously divided into two distinct subcascades. The peak damage occurred around 200 fs with the formation of 237 interstitials, 237 vacancies and 9 antisites. Most of the point defects retracted within the next 1.5 ps leaving behind almost stable defect structures. One structure not observed for $400 \mathrm{eV}$ PKAs is shown Fig. 5(b) with six cations sharing 4 octahedral vacancies. This structure preserves the coordination number of the neighbouring $\mathrm{O}$ ions, but the cations now occupy tetrahedral interstitial sites. Surviving defects were comparable for both $\mathrm{Mg}^{2+}$ and $\mathrm{O}^{2-}$ PKAs but the $\mathrm{Ga}^{3+}$ PKAs produced more damage.

\section{$4.3 \mathrm{MgIn}_{2} \mathrm{O}_{4}$}

Defects that were previously observed at $400 \mathrm{eV}$ for the inverse spinel were produced by $\mathrm{Mg}^{2+}$ and $\mathrm{O}^{2-}$ PKAs, but the In PKAs created much disorder on the In sublattice with the formation of In interstitial-vacancy chains. An average of 15.8 In interstitials remained per trajectory for the In PKAs as compared to 8.5 and 9.0 for the $\mathrm{Mg}^{2+}$ and $\mathrm{O}^{2-}$ PKAs.

The simulation initiated by an In PKA along $\langle 752\rangle$ generated the most damage in this material. A total of 64 interstitials (56.2\% In, $17.2 \% \mathrm{Mg}, 26.6 \% \mathrm{O}), 64$ vacancies and 15 antisites remained in the structure at the end of a 12 ps run. 33 out of the 36 In interstitials were trapped at unoccupied interstices: 28 were taken up at octahedral interstices and only 5 were seen at tetrahedral sites. In these complex environments, there is a strong tendency for the In interstitials to regain the coordination 6 with the anions, explaining the existence of these cation interstitial-vacancy chains.

Fig. 5(c) illustrates the resulting damage for a $\mathrm{Mg}^{2+}$ PKA directed along $\langle 435\rangle$ in the inverse magnesium indate. Typical cation chains can be seen, while the O interstitials formed dancing crowdions, i.e. hop back and forth between the split interstial and crowdion structures and do not attain a permanent stable configuration. However the cation crowdion structures that form remain stable over typical MD time scales.

\subsection{Higher energy Cascades}

A few calculations have also been carried out on larger systems but not in sufficient number to generate good statistics. For the normal aluminate spinel, calculations at a higher energy of $10 \mathrm{keV}$ in a system of $\sim 1$ million ions resulted in similar defect structures as in the lower energy cascades. Cascade 
branching occurred in the $10 \mathrm{keV}$ simulations and spread over a larger volume of the computational cell. Figure 6 gives an example of residual damage from one such cascade triggered by a $\mathrm{Mg}^{2+}$ PKA ending up with a total of 57 vacancies, 57 interstitials and 22 cation antisites. Cascade branching and the reannealing of defects is typical of all the spinel systems, in marked contrast to cascades reported in zircon [20] where large contiguous regions of the crystal structure are damaged and amorphised.

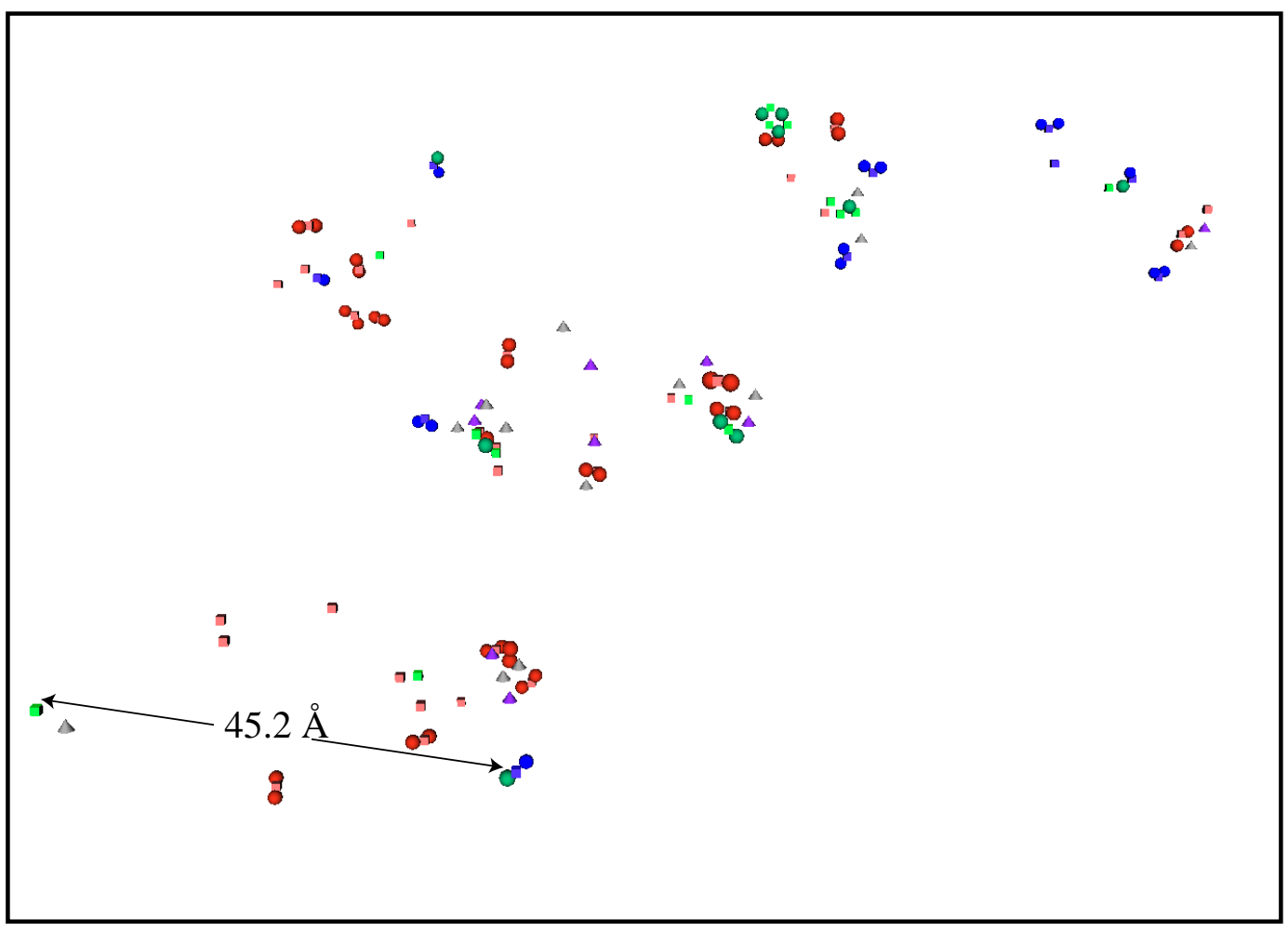

Fig. 6. Damage resulting from a $10 \mathrm{keV}$ cascade in magnesium aluminate spinel for a $\mathrm{Mg}^{2+}$ PKA.

\section{Discussions and Conclusions}

The dynamical simulations resulted in primary defect structures for the three compounds consisting of cation split interstitials centred about a tetrahedral vacancy, oxygen split interstitials, cation antisites and vacancy pairs. The tabulated values show that more defects were created in the inverse spinels partly due to surviving crowdion chains of alternate interstitials and vacancies, for example the rightmost defect structure shown in Fig. 5c (this counts as 3 interstitials and 2 vacancies in our classification scheme). Although cascades initiated in the inverse and half-inverse spinels create more damage during the ballistic phase of the cascade, it is not clear how this damage would evolve in 
the long term. For example, the defect structure shown magnified in figure 5b consists of a region of the crystal which has a local charge of +5 (an extra A and $\mathrm{B}$ ion). The long term survival of such a structure is questionable.

The results show clear differences between the different structures with a lower variety of defects created in normal spinel, especially at the lower energies. For example the low energy $\mathrm{Mg}$ PKA produced defects that were only a split $\mathrm{Mg}$ interstitial and an isolated vacancy while the O PKA produced only damage on the $\mathrm{O}$ sublattice for normal spinel. For the half inverse and inverse spinels, the Mg PKA produced more defects such as the Mg-B cation interstitial about a B ion vacancy and cation crowdion chains, while damage on the cation sublattice for the O PKA was larger than in normal spinel but still exceeded by that on the $\mathrm{O}$ sublattice. The $\mathrm{B}^{3+}$ PKAs created about twice as many $\mathrm{O}$ defects in the half inverse spinel and about three times as many in the fully inverse spinel compared to normal. In the fully inverse spinel there was a tendency for the In interstitials to rearrange about octahedral sites and regain a co-ordination of 6 with the $\mathrm{O}$ ions. An $\mathrm{O}$ vacancy in the fully inverse case had also the effect of causing more local distortion, displacing slightly the neighbouring tetrahedrally-sited In ion.

The cascades in the spinels create defects which do not greatly change the overall crystal structure but which require a certain amount of energy to form. The cation anti-site defects are an example. These require only a small energy to form but are very numerous. On the other hand, the less frequently observed $\mathrm{Al}$ 'ring' defect in magnesium aluminate spinel requires an energy of $10.2 \mathrm{eV}$ to form but involves only the symmetric switching of $3 \mathrm{Al}$ cations to unoccupied tetrahedral sites. This ability to absorb energy, combined with sub-cascade branching which distributes the energy throughout the crystal, rather than a localised thermal spike creating a fully disordered region, means that the crystal structure is able to accommodate a cascade without undergoing radical distortion. Thus defects are more widely spread and not as clustered as in e.g. zircon [20].

\section{References}

[1] J. F. Hurley, J. C. Kennedy, F. W. Clinard Jr., R. A. Youngman, W. R. McDonell, J. Nucl. Mater. 1038104 (1981) 761.

[2] C. Kinoshita, K. Fukumoto, K. Fukuda, G. A. Garner, G. W. Hollenberg, J. Nucl. Mater. 219 (1995) 143.

[3] S. Matsumura, M. Shimada, K. Yasuda, C. Kinoshita, Mat. Res. Soc. Symp. Proc. 792 (2004) 131. 
[4] A. N. Cormack, G. V. Lewis, S. C. Parker, C. R. A. Catlow, J. Phys. Chem. Solids 49 (1988) 53.

[5] K. E. Sickafus, J. M. Wills, N. W. Grimes, J. Am. Ceram. Soc. 82 (1999) 3279.

[6] K. E. Sickafus, L. Minervini, R. W. Grimes, J. A. Valdez, M. Ishimaru, F. Li, K. J. McClellan, T. Hartmann Science 289 (2000) 748.

[7] R. Smith, D. Bacorisen, B. P. Uberuaga, K. E. Sickafus, J. A. Ball, R. W. Grimes, J. Phys.: Condens. Matter 17 (2005) 875.

[8] U. Schmocker, H. R. Boesch, F. Waldner, Phys. Lett. 40A (1972) 237.

[9] U. Schmocker, F. Waldner, J. Phys. C 9 (1976) L235.

[10] J. Ball, R. W. Grimes, D. Price, B. P. Uberuaga, M. O. Zacate J. Phys.: Condens. Matter submitted (2005).

[11] C. R. A. Catlow, K. M. Diller, M. J. Norgett, J. Phys. C: Solid State Phys. 10 (1977) 1394.

[12] J. P. Biersack, J. Ziegler and U. Littmark, The Stopping Range of Ions in Solids, Pergamon Press, Oxford (1985).

[13] R. W. Grimes, S. P. Chen, J. Phys. Chem. Solids 61 (2000) 1263.

[14] M. R. Levy, R. W. Grimes, K. E. Sickafus, Phil. Mag. 84 (2004) 533.

[15] S. Huai, S. B. Zhang, Phys. Rev. B 63 (2001) 045112.

[16] M. O. Zacate, R. W. Grimes, Phil. Mag. A 80 (2000) 797.

[17] W. T. Rankin and J. A. Board, Jr., Proceedings if the 1995 IEEE Symposium on High Performance Distributed Computing, IEEE Computer Society Press Los Alamitos, California (1995) 17.

[18] F. A. Kröger, H. A. Vink, Solid State Physics: Advances in Research and Applications, New-York: Academic (1957).

[19] B. P. Uberuaga, R. Smith, G. Henkelman, A. Voter K. E. Sickafus, A. Cleave, R. W. Grimes Phys. Rev. Lett. 92 (2004) 115505.

[20] K. Trachenko, M. T. Dove, E. K. H. Salje J. Phys.: Condens. Matter L1 (2003) 17. 